\title{
Modelling the Antarctic and Northern Hemisphere ice-sheet changes with global climate through the glacial cycle
}

\author{
W. F. Budd, B. Coutts, Roland C. Warner \\ Antartic CRC, Box 252-80, Hobart, Tasmania 7001, Australia
}

\begin{abstract}
The future behaviour of the Antarctic ice sheet depends to some extent on its current state of balance and its past history. The past history is primarily influenced by global climate changes, with some small amount of local feedback, and by sea-level changes generated primarily by the Northern Hemisphere ice-sheet changes, again with a small amount of feedback from the Antarctic ice sheet. An ice-sheet model which includes ice shelves has been used to model the Antarctic region and the whole Northern Hemisphere high-latitude region through the last ice-age cycle. For the climate forcing, the results from the global energy-balance model of Budd and Rayner (1990) are used. These are based on the Earth's orbital radiation changes with ice-sheet albedo feedback. Additional sensitivity studies are carried out for the amplitudes of the derived temperature changes and for changes in precipitation over the ice sheets. For the Antarctic snowaccumulation changes, the results from the Vostok ice core are used with proportional changes over the rest of the ice sheet. For the sea-level variations, the results generated by the Northern Hemisphere ice-sheet changes provide the primary forcing, but account is also taken of the feedback effects from bed response under changing ice and ocean loading and from the Antarctic changes.

The results of the modelling provide a wide range of features for comparison with observations, such as the margins of maximum ice extent. For the Northern Hemisphere the results indicate that the peak mean temperature shift required for the ice-edge region is about $-12 \mathrm{C}$, whereas outside the ice-sheet region this change is smaller but over the ice sheets it is larger. For the Antarctic region during the ice age the interior region decreases in thickness, due to lower accumulation, while the grounding-edge region expands and thickens due to the sea-level lowering. As a result, the derived present state of balance shows a positive region over most of inland East Antarctica, whereas coastal regions tend to be nearer to balance, with some slightly negative regions around some of the large ice shelves and coastal ice streams which are still adjusting slowly to the post-ice-age changes of sea level and accumulation rates.
\end{abstract}

\section{BACKGROUND AND AIMS}

The aim of this paper is to report further progress on a project to simulate the changes of the whole global climate system through the period of the ice ages, forced only by the variations in the external solar radiation regime associated with the Earth's orbital changes. Changes of the internal components of the global climate system, involving the atmosphere, ice and ocean, need to be prognostic. It is still not computationally possible to run a high-resolution complete global climate system model continuously through multiple ice-age cycles. Therefore at this stage we use a hierarchy of models with asynchronous coupling to simulate the changes in a preliminary way and to carry out sensitivity studies of various components of the system.

Atmospheric-sea-ice general circulation models (GCMs) and atmosphere ocean sea-ice GCMs can be used to compute "snapshot" climatologies at key epochs of the time series for climate change through the period, such as the Last Glacial Maximum (LGM), the Last Interglacial (LIG) and other stadials, interstadials or periods of rapid change. Global-climate energy-balance models (EBMs) are used, with certain features parameterised from the GCMs, to run continuously through the ice-age cycles, coupled to ice- sheet models and driven by the external radiation variations from the orbital changes.

Ice-sheet models are driven by the output from the EBMs but also feed back into the EBM the results of the ice-sheet changes. Because the ice-sheet changes are relatively slow it is found that the asynchronous coupling allows this feedback to be carried out adequately at intervals of about 1000 years (Budd and Rayner, 1990). The Northern Hemisphere and Southern Hemisphere domains for ice cover are treated separately, connected only by the synchronous climate of the EBM and a common sea level with which they both interact.

For the Antarctic ice sheet the forcing of changes comes primarily from the local orbital radiation variations plus the effects of the Northern Hemisphere ice-sheet changes which influence the Antarctic temperature and accumulation rate and the sea level.

Previous work by Budd and Smith (1981, 1987), who modelled the North American ice sheet in response to orbital forcing, found that although the summer radiation changes provided the crucial external driver of the ice-age changes, it was the internal feedback of the ice-sheet cover which dominated the time series for global mean temperature. It was found that a key requirement for the ice sheets to 
develop in the time available was for the orbital forcing to give rise to a temperature drop of about $4^{\circ} \mathrm{C}$ over summer near $70^{\circ} \mathrm{N}$ after the LIG. The ice-sheet cover at maximum provided additional temperature lowering in excess of $5 \mathrm{C}$. To remove the ice sheets after the LGM, the orbital forcing needed to provide the equivalent of about $6{ }^{\circ} \mathrm{C}$ warming in the absence of ice sheets. Such equivalent warming has been confirmed by GCM results (e.g. Mason, 1979).

Investigations with annual-cycle orbital forcing and high-resolution topography, using a global EBM, by Budd and Rayner (1990, 1993) clarified the temperature changes resulting from the orbital changes alone and combined with the ice-sheet albedo effect. It was also found that the global annual mean temperature was negligibly influenced by the orbital radiation changes and was almost entirely due to the icecover and associated changes, such as sea level, and possibly smaller in-phase effects including atmosphere composition.

A further important result from the EBM with $1^{\circ}$ latitude resolution was that there were very large and sharp gradients of surface summer temperature change near the edge of the ice sheets from about $-30^{\circ} \mathrm{C}$ over the ice sheet to about $-6^{\circ} \mathrm{C}$ over land areas south of the ice sheets ( $\mathrm{cf}$. Budd and Rayner, 1990, fig. 2).

Similar results were found at coarser resolution with the GCMs (e.g. Gates, 1976a, b; Manabe and Broccoli, 1985; Rind, 1987). The strong influence of the ice sheet on the global temperature was also illustrated by the GCMs, particularly those of higher resolution. The strength of this icesheet albedo feedback is dependent on the prescribed albedo, which is poorly known for the ice sheets and which could vary from near 0.9 for the high interior to 0.4 over the high ablation zone near the edge. This question has been examined here by sensitivity tests to temperature forcing over the ablation zone at the edge of the ice sheet to derive the best-fit mean temperature drop at the LGM for the Northern Hemisphere appropriate for the ice-edge region.

Corresponding results from the GCM results of Gates (1976a, b) using the earlier CLIMAP (1976) data are shown in Table 1. These results are used in preference to those from the later CLIMAP data, due to the problems raised by many workers (e.g. Rind and Peteet, 1985; Webb and others, 1997).

Observational evidence for the large gradient in ice-age temperature differences from the land south of the ice edge to the interior was provided by Cuffey and others (1995) for the central ice-sheet region of Greenland, and by Levesque and others (1997) for the North American ice-margin region. Coupled modelling of the climate-ice-sheet system for the Northern Hemisphere through the glacial cycle was also carried out by Deblonde and Peltier (1991), Huybrechts

Table 1. Differences in ice-age temperature changes across iceedge regions from land to ice sheet (derived from Gates, $1976 a, b)$

Mean surface temperature differences (ice age present) for July

Northern Hemisphere ice-free land average $\quad-6.6^{\circ} \mathrm{C}$

Land adjacent to ice sheets

Europe

North America

Ice-sheet covered regions average

Ice-sheet centre region
$11 \mathrm{C}$ (range $-15^{\circ}$ to $-6^{\circ} \mathrm{C}$ )

$-12^{\circ} \mathrm{C}$ (range $-15^{\circ}$ to $-7^{\circ} \mathrm{C}$.

$-15.3^{\circ} \mathrm{C}$

$25 \mathrm{C}$ and T'siobbel (1995) and Marsiat (1995). The present study also includes ice shelves and obtains a reasonable match to estimated LGM ice limits compiled from observations (e.g. Grosswald and Hughes, 1995).

\section{OUTLINE OF MODELLING OF THE NORTHERN HEMISPHERE ICE-AGE GYCLE}

The domain for the Northern Hemisphere used here is taken from the North Pole to $30^{\circ} \mathrm{N}$ on a stereographic projection using a rectangular grid of $50 \mathrm{~km}$ based on the scale of $50^{\circ} \mathrm{N}$ latitude. This work is taken as preliminary for sensitivity tests before converting to a corresponding sphericalsurface domain. The topography for land and seabed are taken from a data base of approximately $10 \mathrm{~km}$ spacing and averaged over the domain-scale gridpoints.

The ice-sheet model is similar to that used previously for the Antarctic by Budd and Jenssen (1989) and Budd and others (1994). Because of space limitations, only the most pertinent points are emphasised here. A detailed description of the model is given in Mavrakis (1993).

The model includes a simplified ice-shelf formulation for rapid computation over arbitrary domains through the iceage cycles. The model derives the loci of centre-line flows from surface-slope vectors and takes account of transverse and longitudinal stresses in a simplified manner where the ice shelf is bounded, or grounding points occur. At ice fronts the free-floating strain rate is used following Weertman's (1957) formulation (cf. Budd and others, 1987). A calving criterion is applied to the floating ice when the ice thickness reduces to below $250 \mathrm{~m}$. Although this formulation is crude compared to a complete two-dimensional stress-field model of the type developed by MacAyeal and Thomas (1982), the present model provides a reasonable first-order representation of existing Antarctic large ice shelves in velocity, thickness and extent, and is also relatively rapid to compute for ice-age cycles. An initial basal melt rate for the Arctic Ocean of $0.2 \mathrm{~m} \mathrm{a}^{1}$ is applied and this is reduced during the ice age with lower sea level. For the Northern Hemisphere ice sheets, much of the basal zone in the low-elevation regions is found to be near pressure-melting point for most of the time, so the flow parameters for temperate ice from Budd and Jacka (1989) are used with sensitivity studies around these values for ice deformation and sliding. The deformation and sliding relations as outlined by Budd and Jenssen (1989) provide input to the continuity equation.

At the upper surface, the net accumulation is obtained from an initial distribution of precipitation (or net precipitation minus evaporation) plus an ablation rate based on mean summer temperature, following Budd and Smith (1987). The mean summer temperatures are taken from compilations of present surface temperature and decrease with height using a prescribed lapse rate of $6.5^{\circ} \mathrm{C} \mathrm{km}^{-1}$. As the ice-sheet elevation increases, the net surface precipitation decreases, according to the "elevation-desert effect" described by Budd and Smith (1981).

A number of data sources for the present distribution of surface temperature and precipitation were used. These include Jaeger (1976), Melbourne University GCM and the European Centre for Medium-range Weather Forecasting Global Analysis Archives.

Sensitivity studies were carried out to examine the consequences of the relatively large differences between these 
datasets and to examine possible changes in precipitation for different glacial epochs, based on the results of GCM modelling. Although large decreases in snow accumulation occur over the ice-covered areas during the glacial periods, the dominant changes are primarily covered by the elevation-desert effect.

A simple non-linear isostatic bed response formulation is used as given by Budd and Smith (1981) as follows:

$$
\frac{\mathrm{d} b^{*}}{\mathrm{~d} t}=\gamma\left(b^{*}-\frac{\rho_{\mathrm{i}}}{\rho_{\mathrm{m}}} Z\right)^{2}
$$

where $b^{*}$ is the bed elevation difference from equilibrium as a function of time $(t)$ for an ice-thickness departure from equilibrium $Z$ with $\rho_{\mathrm{i}}$ and $\rho_{\mathrm{m}}$ the effective densities for ice and mantle, respectively. The constant $\gamma$ used here has a value of $0.0005 \mathrm{~km}^{-1} \mathrm{a}^{-1}$. The value of $\rho_{\mathrm{m}} / \rho_{\mathrm{i}}$ is taken as 3.3 .

The present bed has been relaxed upwards by an amount corresponding to the residual depression remaining at the end of the simulation, reaching the present conditions following the ice-age cycle. The constants are chosen to match the total uplift since the ice age and the present uplift rate for the Hudson Bay region.

The temperature forcing through the ice-age cycle is taken from the EBM results of Budd and Rayner (1990) with combined radiation and ice-sheet albedo feedback. Because the temperature of the ablation zone was not well resolved by the EBM (or the GCMs), the magnitude of the tempera- ture shift here was taken as an unknown scaling factor for that forcing, and a series of simulations was carried out to derive the best fit for the ice edge at LGM. A large number of additional simulations were carried out to test the sensitivities to the wide range of variables as described above. Only a few of the major results can be given here.

\section{RESULTS OF THE NORTHERN HEMISPHERE SIMULATIONS}

Figure 1 shows how the maximum ice extent at LGM from the model changes with the magnitude of the maximum temperature drop at LGM $(\Delta T)$ in the marginal zone of the ice sheets for $\Delta T=-4,-8,-12,-16 \mathrm{C}$. The results displayed are selected from a series with $1^{\circ} \mathrm{C}$ steps of $\Delta T$ and from a large number of sensitivity runs with variations in the precipitation and other parameters. The case for $\Delta T=-12^{\circ} \mathrm{C}$ matches most closely the maximum extent from compilations of observations for the complete Northern Hemisphere (e.g. Denton and Hughes, 1981; Grosswald, 1988; Grosswald and Hughes, 1995). Note that the steep marginal ablation zone for the ice sheets tends to be sub-grid scale for the GCMs and the EBM of Budd and Rayner (1990). The temperature shift of $\Delta T=-12^{\circ} \mathrm{C}$ for the ice edge resolves better the change given by the EBM, going from $-6^{\circ} \mathrm{C}$ over land to $-30^{\circ} \mathrm{C}$ over the ice cap, and the similar results for the GCMs given in Table 1.

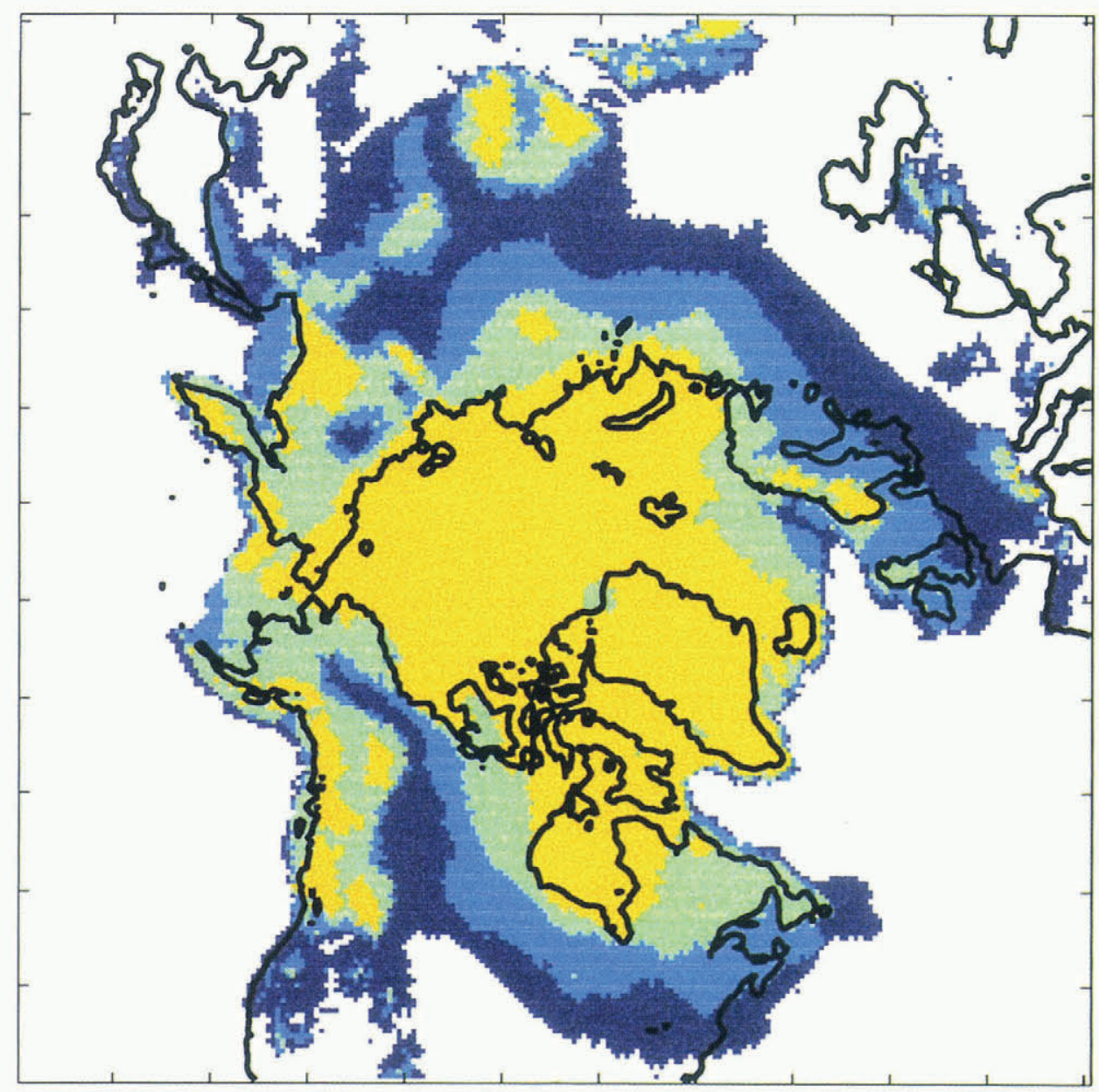

Fig. 1. Variation in the modelled LGM extent of ice for the North Polar region, shown as a function of maximum temperature lowering $\left(\Delta T_{\mathrm{m}}\right)$ appropriate for the ice-edge region. Ice-edge positions are shown by increasing areas in colour shading (from yellow to dark blue) for $\Delta T_{\mathrm{m}}=-4,-8,-12,-16^{\circ} \mathrm{C}$. The value of $\Delta T_{\mathrm{m}}=-12 \pm 1$ C provides the closest match to observational-based LGM reconstructions. 


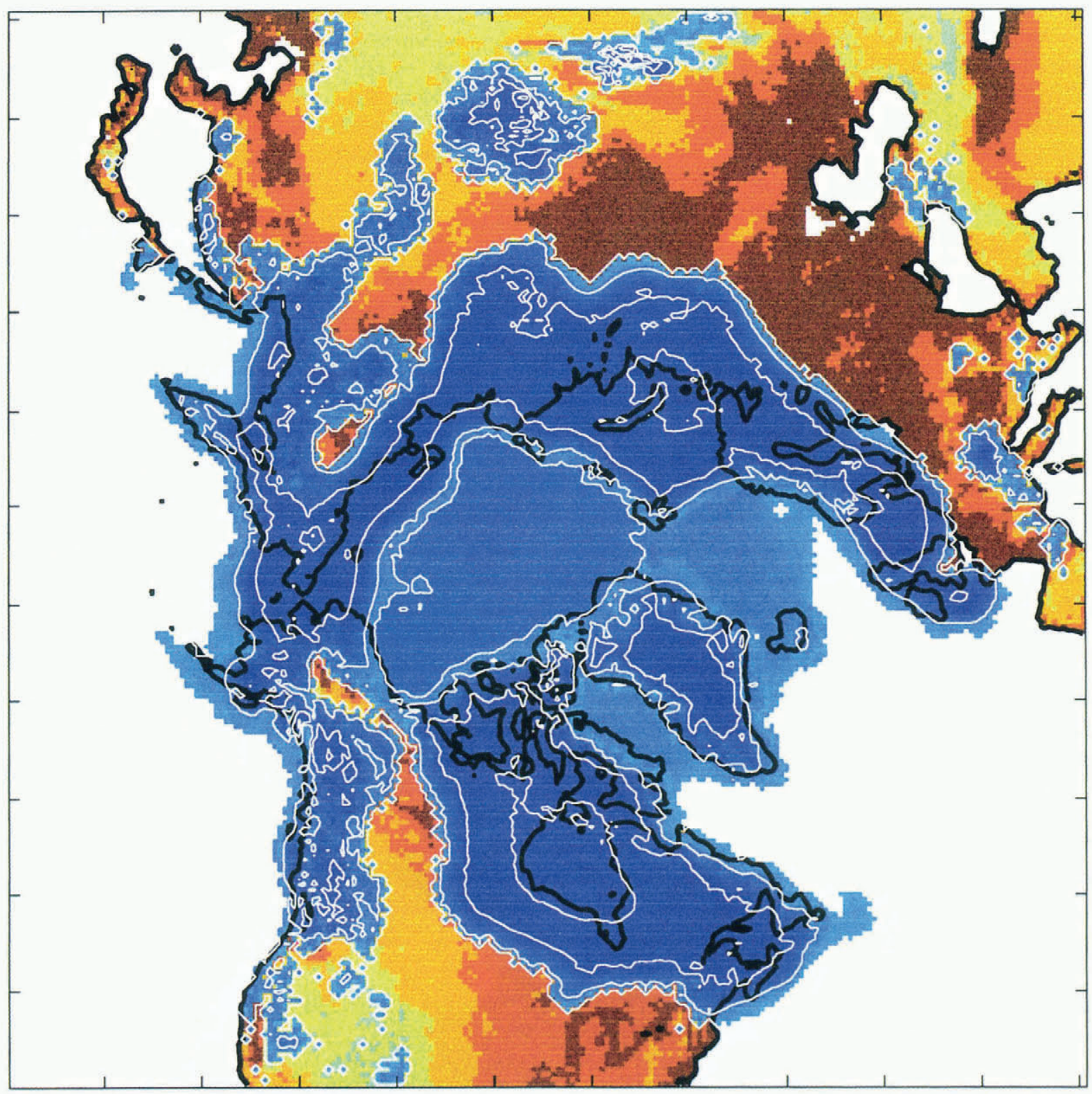

Fig. 2. Distribution of ice thickness at LGM over the Northern Hemisphere topography, showen for the model run with $\Delta T=-12^{\circ} \mathrm{C}$. The distribution of grounded and floating ice showe considerable similarity to that of the palaeo-reconstruction of Grosswald and Hughes (1995). Contours for ice thickness are shown for 0, 1, 2, $3 \mathrm{~km}$ and for the land topography with colour boundaries 0, 0.3, 0.5, $1,2,3 \mathrm{~km}$.

The temperature drop around the ice-edge region should not be expected to be uniform, and the results obtained here indicate that differences of $\pm 1^{\circ} \mathrm{C}$ in different locations could account for discrepancies in the maximum ice-edge positions. Similar effects are found from variations of about $\pm 20 \%$ in the local precipitation rate for a region. The pattern for the distribution of ice thickness at LGM for the case with $\Delta T=-12^{\circ} \mathrm{C}$ is shown in Figure 2. Quite close resemblance is seen with the Grosswald and Hughes (1995) compilation for extent, and the Grosswald (1988) reconstruction for ice thickness, although it is recognised that the representation of the extent of ice in Siberia at that time is still controversial.

Nevertheless it appears from the model that the development of marine ice sheets around the Arctic Islands and a floating ice shelf over the Arctic Ocean during the ice age would be a clear result of the cooling and lowered firn line. The pattern of flow of the ice shelf across the Arctic from Euro-Asia and North America to Fram Strait, east of Green- land, resembles closely the pattern seen from apparent ice scour and ice-rafted debris by Bischof and Darby (1997).

Figure 3 shows the corresponding distribution of ice over land at the end of the glacial-cycle simulation corresponding to the present. The distribution gives a reasonable representation of the present observed ice distribution and provides a useful test for the present climatic forcing for temperature and precipitation, as well as for the model. Some features, such as the Barnes Ice Cap on Baffin Island, are found to exist in the model for the present only as a result of the glacial cycle. This is because the bedrock elevation is too low, without the ice cover, to form a positive net accumulation region under the present climatic conditions.

The pattern of temperature forcing and ice-volume response (for grounded ice, floating ice and the fraction of ice volume affecting sea-level change) is shown for the case given in Figures 2 and 3, together with the bed-depression volume for the ice-age cycle in Figure 4. The Northern Hemisphere ice-volume fraction associated with sea-level 


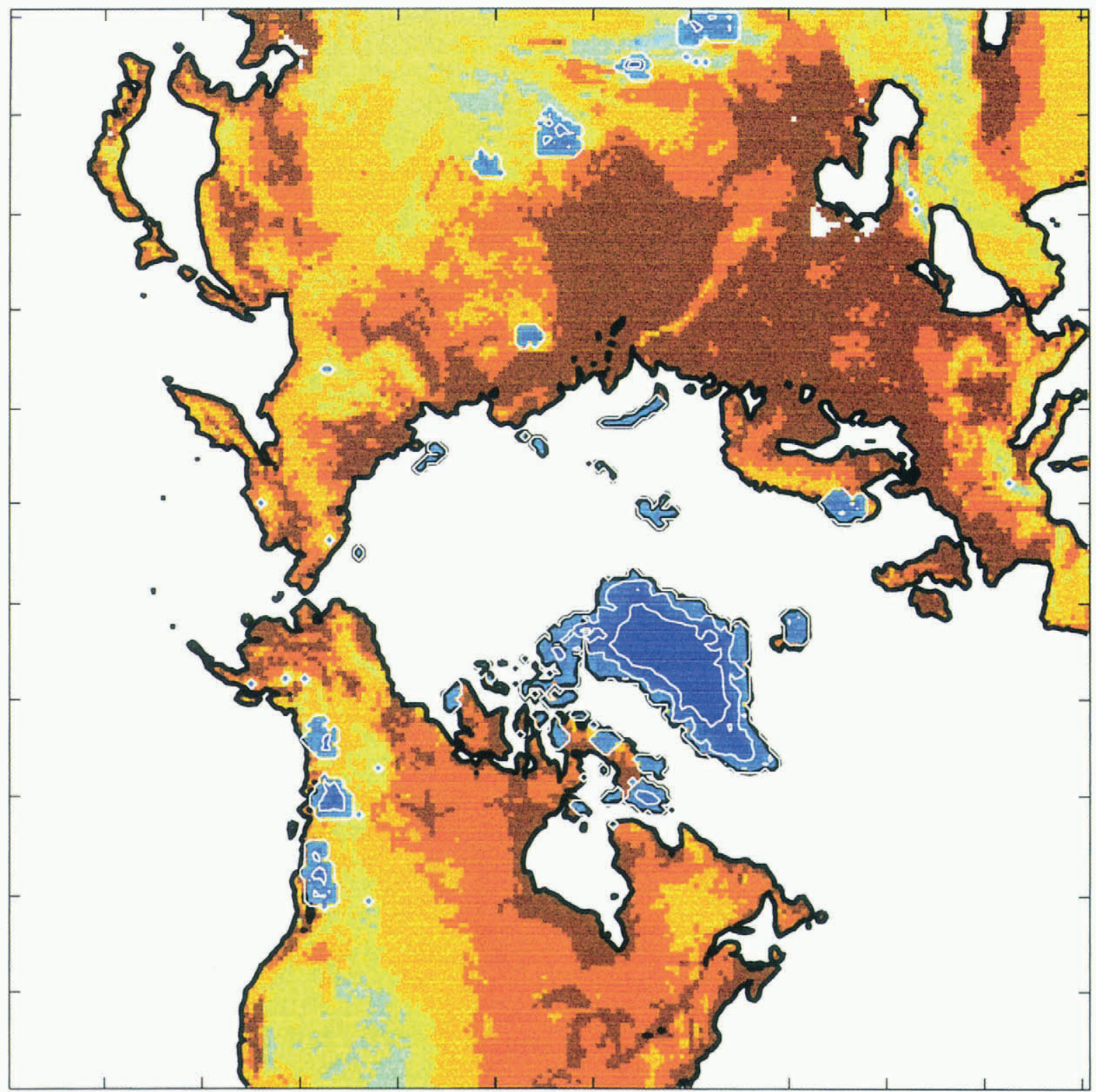

Fig. 3. Present-day ice cover on land produced by the model at the end of the run through the glacial cycle with $\Delta T_{\mathrm{m}}=-12^{\circ} \mathrm{C}$, following the LGM of Figure 2. The Greenland ice sheet and Barnes Ice Cap remain from the glacial conditions. Contours for ice thickness and land elevation are the same as for Figure 2.

change, when compensated for by the bed depression, and ocean-bed responses, agrees reasonably with estimates of low sea level at LGM without the need for an additional large Antarctic contribution. In fact, the results presented below indicate that the Antarctic contribution to sea level for the bulk of the ice age is found to be negative, with a smaller ice-sheet volume but greater extent at LGM than at present.

\section{ANTARCTIC ICE SHEET AND FORGING FOR THE GLACIAL GYCLE}

Initially, it is not known what the extent of disequilibrium is for the present Antarctic bedrock isostatic adjustment. The data for the model are based on the $20 \mathrm{~km}$ grid dataset described by Budd and Jenssen (1989). The ice-sheet temperatures and ice-flow parameters were based on the results for the steady state for the present regime and the match between the computed surface velocities and observed velocities as given by Budd and Jenssen (1989). For the model simulations the procedure adopted is as follows. The ice is removed and the bed relaxed up to equilibrium. Then the ice sheet is simulated from a period prior to the glacial maximum which preceded the Last Interglacial through to the present (approximately $150-0 \mathrm{ka} \mathrm{BP}$ ). The forcings for the ice-sheet changes are eustatic sea level (primarily resulting from the Northern Hemisphere ice changes), the net accumulation rate and the mean climatic temperature changes. The accumulation-rate changes are based on the results from the Vostok ice core given by Jouzel and others (1987) and Lorius and others (1989). It is assumed here that the broad changes in accumulation rate over the Antarctic continent were proportional to those at Vostok taken as a percentage change of the present accumulation rate. Additional changes to this base rate are derived from the changes in ice-sheet elevation above sea level as given by the elevation-desert formulation described above.

The temperature changes come from the EBM, using combined radiation and ice-sheet effects, and including the 

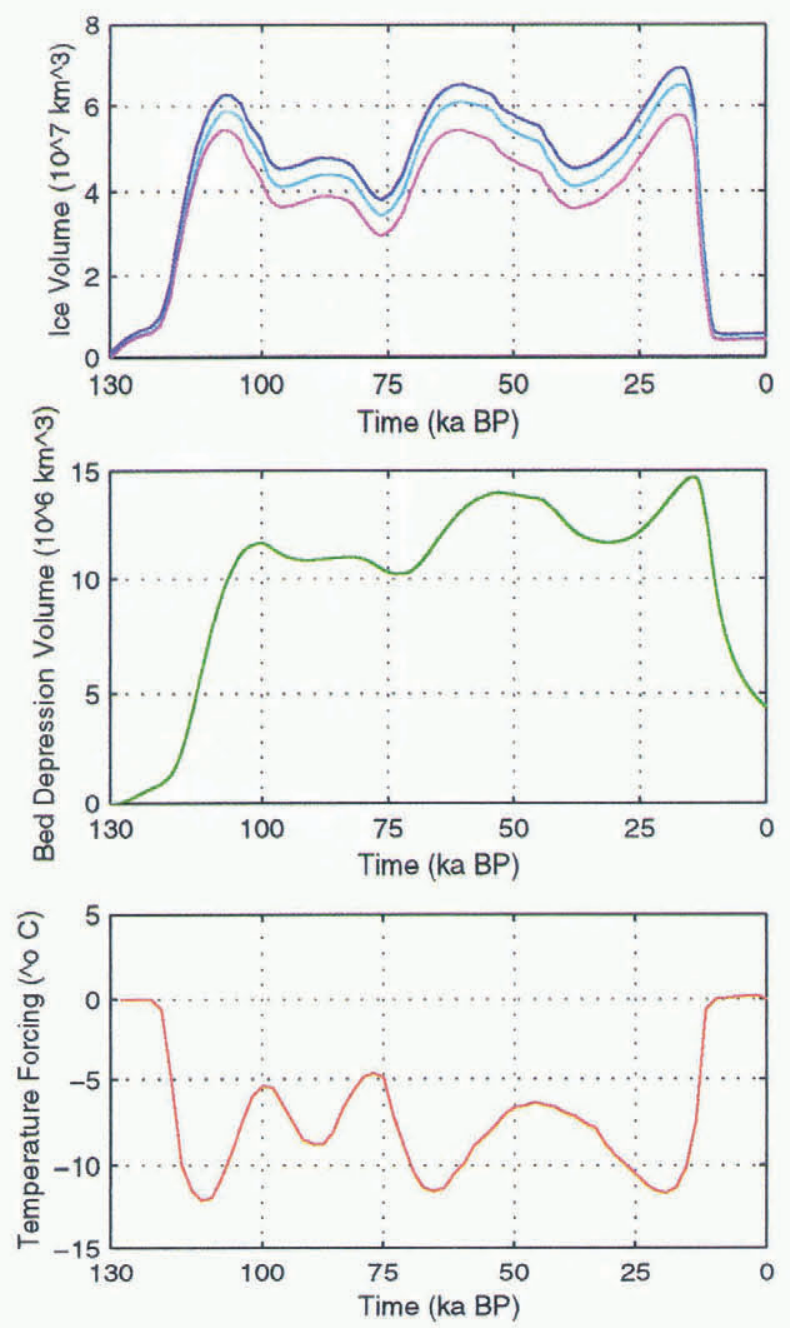

Fig. 4. Time series for the temperature forcing (for $\Delta T_{\mathrm{m}}=$ $-12 \mathrm{C}$ ) from the combined orbital radiation changes and ice-sheet albedo feedback (bottom), together with the icevolume responses (top), for total ice (purple), grounded ice (blue), ice volume affecting sea level (red) and the volume of bedrock depression.

changes of the sea-ice extent, as described by Budd and Rayner $(1990,1993)$. These results provide a close match to the Vostok $\delta^{18} \mathrm{O}$ proxy temperature record from Lorius and others (1985) and Jouzel and others (1987), more particularly for the winter season, over which most of the net accumulation occurs.

These forcing changes were applied to simulate changes of the Antarctic ice sheet, from before the last interglacial to the present, for a large number of runs to test the model's sensitivity to adjustments to the magnitudes of the prescribed forcing and to uncertainties in the ice flow and sliding parameters used in the model. Some simulations have been run with the $20 \mathrm{~km}$ grid resolution, but because of the long computation time required a reduced $100 \mathrm{~km}$ grid has been used for a much larger number of sensitivity studies. It has been found that the large-scale average changes are well simulated with the $100 \mathrm{~km}$ grid, but significant differences occur in the detail, particularly around the coast.

\section{RESULTS FOR THE ANTARGTIC GLACIAL GYCLE SIMULATION}

In order to examine the relative influence of the different https://doi.org/10.3189/1998AoG27-1-153-160 Published online by Cambridge University Press components of the forcing, the changes were simulated separately for the individual factors, as well as in combination. The results show that the effect of eustatic sea-level changes alone resulted in ice grounding-line advance during the glacial periods (particularly around the large ice shelves), with thickening in the interior and an increase in ice volume. By contrast, the changes in accumulation rate alone caused thinning of the ice sheet and a reduced ice flux at the edge. For the combined effects, the impact of the reduced accumulation dominates for the whole ice sheet, but regionally, particularly around the large ice shelves, the eustatic sea-level changes cause large changes in the area of grounded ice.

These results are illustrated by the ice-volume time series shown in Figure 5, giving separately the results for the changes of accumulation and sea level alone and then combining them. These results imply that the changes in Antarctic ice volume during the glacial cycle could have a small offset effect on global sea-level changes produced by the Northern Hemisphere ice changes. The similar study by Huybrechts $(1990,1992)$ obtained a net increase in Antarctic ice volume at LGM. The differences between those
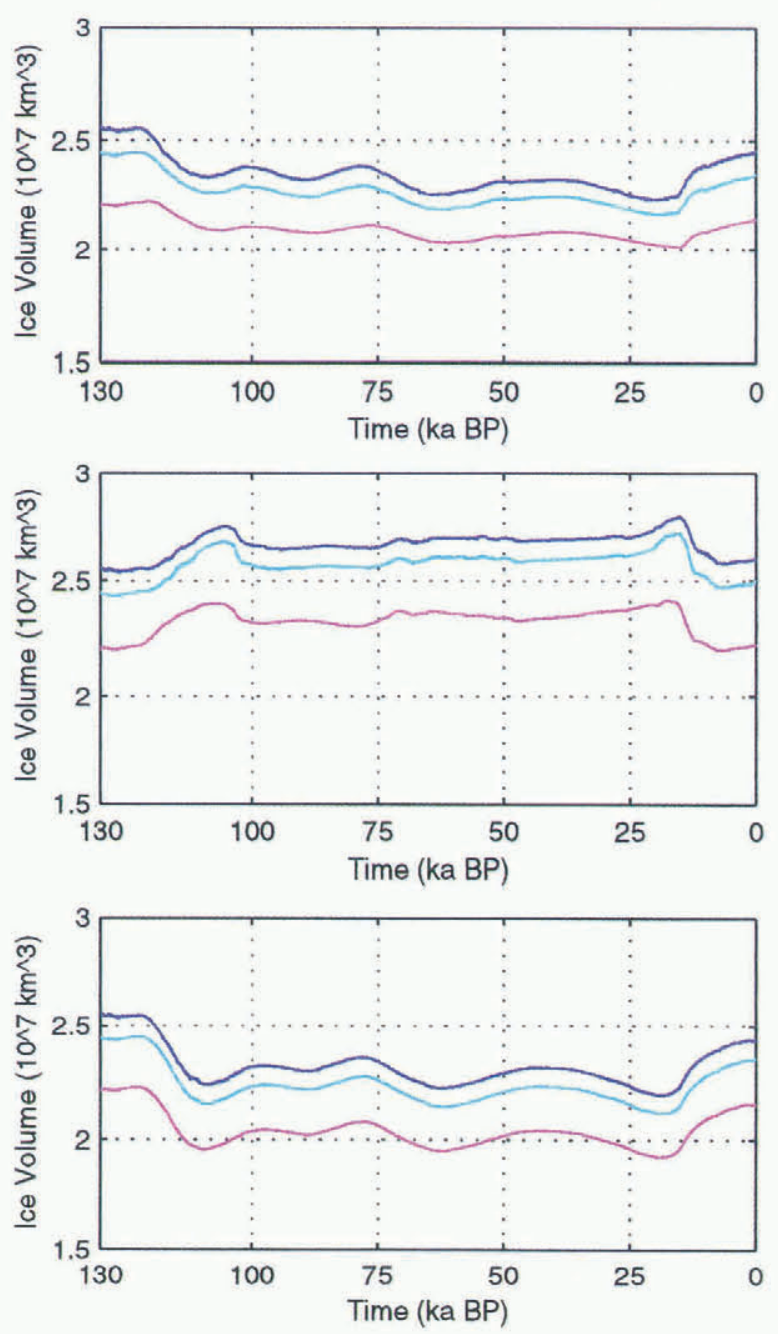

Fig. 5. Time series for Antarctic ice-volume changes (total, grounded and affecting sea level, as in Fig. 4) through the last glacial cycle from the model for the separate forcing of accumulation changes, sea-level changes and combined accumulation and sea-level changes. It appears that the accumulationchange effects are dominant for the ice volume at LGM. 

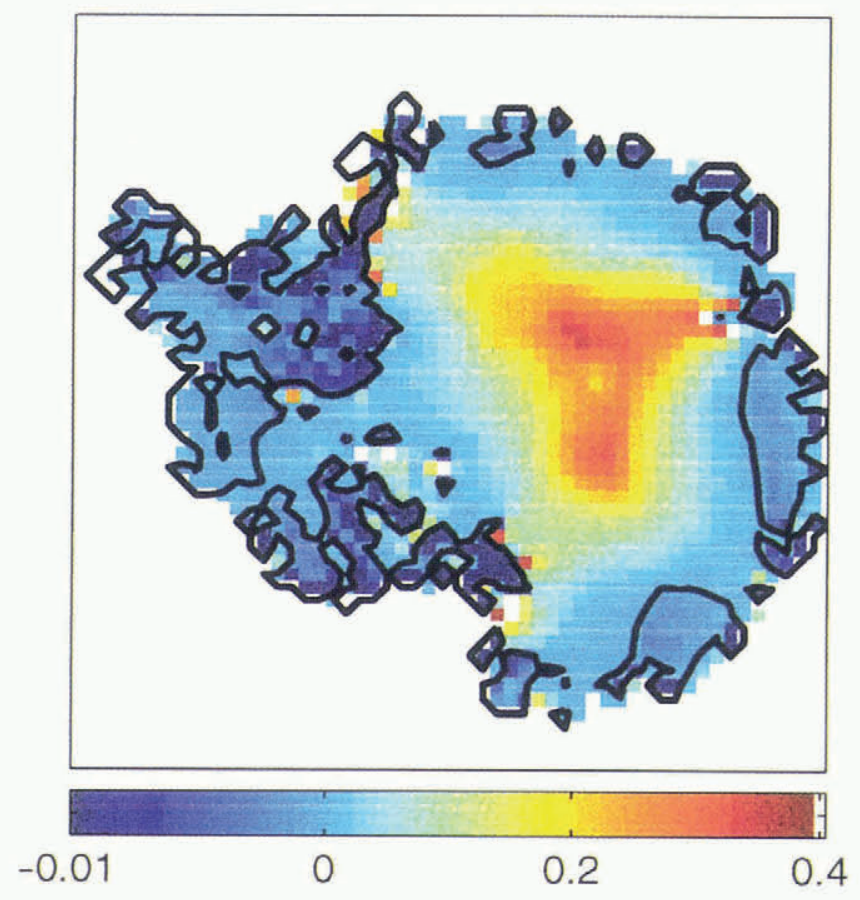

\begin{abstract}
Fig. 6. The near to present (pre-industrial) state of balance of the Antarctic ice sheel (averaged over the last $2 \mathrm{ka}$ ) is shown from the model (with $100 \mathrm{~km}$ grid) after the end of the ice-age cycle to the present. The state of balance is expressed as the rate of change of ice thickness as a fraction of the present accumulation rate. The interior of East Antarctica shows thickening, whereas in coastal regions and in parts of West Antarctica slight thinning tends to predominate. The zero line is shown bold, and the colour scale for the small negalive values has been expanded.
\end{abstract}

results and the results obtained here appear to be due to several factors. These include the different forcings used for sea level and the accumulation-rate pattern. The formulation of ice sliding was also different and the models are particularly sensitive to the sliding relation and the values of the parameters used in it. Finally, the differences in the ice-shelf models may also be an important factor in the different changes in ice thickness over the large ice-shelf areas.

The model results presented here indicate that the simulated Antarctic ice-sheet margin at LGM was more advanced and thicker than for the present ice sheet, due to the lower sea level. At the same time, there was reduced thickness in the interior, particularly in East Antarctica, due to the lower accumulation rates. These characteristics together resulted in a slightly smaller net grounded ice volume than that of the present ice sheet.

These results are still regarded as preliminary because the changes in West Antarctica, particularly in the region just inland of the large ice shelves, are very sensitive to the model flow and sliding parameters and to the past accumulation rates. Observations giving grounding-line positions at the LGM and past accumulation rates are particularly valuable in constraining the model results in this regard. Nevertheless the changes for East Antarctica appear to be reasonably robust, and so we next examine the implications of the model for the present state of balance of the Antarctic ice sheet.

\section{ASSESSMENT OF THE GURRENT STATE OF BALANCE AND RATE OF CHANGE OF THE ANTARCTIC ICE SHEET}

The time series for ice-volume change of the Antarctic ice sheet from the model displayed in Figure 5 shows a rapid increase in volume after the LGM following the accumulation-rate increase. By about 8000 years ago this rate of change had very much decreased as the ice approached the new state of balance with the Holocene climate. By the present, the icesheet model volume continues to increase by about $0.025 \mathrm{~km}^{3} \mathrm{a}^{-1}$, which is equivalent to only about $0.08 \mathrm{~mm} \mathrm{a}^{-1}$ of sea-level lowering.

The distribution of the imbalance, however, is far from uniform, with the more slowly responding interior of East Antarctica (particularly above $3000 \mathrm{~m}$ ) still building up, whereas the more coastal areas (primarily below $2000 \mathrm{~m}$ ) are more nearly in balance, or even in slight negative balance, from the responses to sea-level change and the slower subsequent bedrock adjustment.

These features are illustrated in Figure 6 which shows the model results for the present rate of change of the ice sheet at the end of the ice-age simulation (averaged over the last 2000 years) expressed as a fraction of the present accumulation rate. The interior region of East Antarctica shows a positive balance generally between $5 \%$ and $20 \%$ but reaching $40 \%$ at dome summits. This positive-balance region extends to near the grounding line in the Lambert Glacier valley, a result which appears to be supported by observations in that region (Allison, 1979; Higham and others, 1997). Around the coastal regions generally, the imbalance values tend to be variable but typically less than $\pm 5 \%$.

In West Antarctica the large interior negative-balance regions are primarily related to the large grounding-line shifts due to the eustatic sea-level changes. It should be emphasised that it appears from the ice-core data (e.g. from Vostok, Byrd, Law Dome), as well as the modelling, that this gradual approach towards equilibrium has been taking place over many thousands of years through the Holocene, right up until the pre-industrial period, last century, before anthropogenic influences on climate may have become significant. The results presented by Smith and others (1998) indicate that since last century the effects of global warming appear to have been increasing the Antarctic net accumulation rates by up to $5-10 \%$ by the present. This recent increase towards a positive net balance for the present would need to be added to the post-ice-age long-term changes modelled here to give the state of balance and current rate of change of the Antarctic ice sheet for the present day.

\section{CONCLUSIONS}

It is apparent that the Northern Hemisphere ice changes through the glacial cycle can be reasonably well simulated from the orbital radiation changes plus the ice-sheet albedo feedback. This generates the global sea-level and climate changes that together with the local radiation changes drive the Antarctic ice-sheet changes. The ice-core records provide additional information for the time changes of accumulation rates and temperature. The applied forcing results in an ice-age advance of the grounding line of the Antarctic ice sheet, with thickening around the edge, but with thinning in the interior due to the reduced accumula- 
tion rate. A small volume decrease, equivalent to about $5 \mathrm{~m}$ of sea-level rise, occurs for the Antarctic model at the LGM relative to the present.

After the LGM the modelling for Antarctica gives retreat at the edge, from the rise in eustatic sea level, but thickening in the interior, from the increase in accumulation rate.

By the present century the model was close to the present ice-sheet configuration, giving a state close to overall balance and contributing only $0.08 \mathrm{~mm}$ a ${ }^{-1}$ to sea-level lowering. However, in the interior of East Antarctica there was still a net positive imbalance of about $20 \%$, where the accumulation rate was low, and small negative balances of around $5 \%$ occurred in places around the coast, and of 5 $10 \%$ over a large part of West Antarctica. It should be noted, however, that the derived rates of change for West Antarctica may not be so robust, even though the resulting configuration derived for the present is close to that observed. Since last century the effects of global warming appear to have contributed an additional 5-10\% towards a net positive balance (Smith and others, 1988).

These results combined are in line with the recent massbalance assessments by Budd and Warner (1996), giving above $+30 \%$ positive balance over the inland region of Wilkes Land and under $+10 \%$ nearer the coast. The extension of the higher positive balance of the interior region down to Lambert Glacier is also well supported by the observations reported by Allison (1979) and Higham and others (1997).

Under a continuing global warming trend, resulting from increasing greenhouse gases, the positive balance inland can be expected to increase further until coastal basal melt and increased flow provide compensation (cf. O'Farrell and others, 1997). The ice-sheet configuration obtained here with slow regional changes of different sign, but near-zero overall net balance, provides a reasonable starting-point (at pre-industrial times) for computing the Antarctic ice-sheet changes associated with global change, from last century to the present, and extending into the future.

\section{REFERENCES}

Allison, I. 1979. The mass budget of the Lambert Glacier drainage basin, Antarctica. f. Glaciol., 22 (87), $223-235$.

Bischof. J. and D. A. Darby. 1997. Mid- to Late Pleistocene ice drift in the western Arctic Ocean: evidence for a different circulation in the past. Science, 277 5322), 74-78.

Budd, W. F. and T. H. Jacka. 1989. A review of ice rheology for ice shect modelling. Cold Reg. Sci. Technol., 16 2), 107-144.

Budd, W. F. and D. Jenssen. 1989. The dynamics of the Antarctic ice sheet. Ann. Glaciol., 12, 16-22.

Budd, W. F, and P. Rayner. 1990. Modelling global ice and climate changes through the ice ages. Ann. Glaciol., 14, $23-27$.

Budd, W. F and P. Rayner. 1993. Modelling ice sheet and climate changes through the ice ages. In Peltier, W. R., ed. Ice in the climate system. Berlin, etc., Springer-Verlag, 291-319. (NATO ASI Series I: Global Environmental Change 12 .

Budd. W. F. and I. N. Smith. 1981. The growth and retreat of ice sheets in response to orbital radiation changes. International Association of Hydrological Sciences Publication 131 Symposium at Canberra 1979 - Sea Level, Ice and Climatic Change), 369-409.

Budd, W. F, and I. N. Smith. 1987. Conditions for growth and retreat of the Laurentide ice sheet. Géogr. Phvs. Qual., 41 (2), 279-290.

Budd, W. F. and R. C. Warner. 1996. A computer scheme for rapid calculations of balance-flux distributions. Ann. Glaciol., 23, 21-27.
Budd, W. F.. B. J. McInnes, D. Jenssen and I. N. Smith. 1987. Modelling the response of the West Antarctic ice sheet to a climatic warming. In Van der Veen, C. J. and J. Oerlemans, eds. Dynamics of the Itest Antarctic ice sheet. Dordrecht, etc., Kluwer Academic Publishers, 321-358.

Budd. W. F., D. Jenssen, E. Mavrakis and B. Coutts. 1994. Modelling the Antarctic ice-sheet changes through time. Ann. Glaciol.. 20, 291-297.

CLIMAP Project Members. 1976. The surface of the ice-age Earth. Science, $191(4232), 1131-1137$.

Cuffey, K. M., G. D. Clow, R. B. Alley, M. Stuiver, E. D. Waddington and R.W. Saltus. 1995. Large Arctic temperature change at the WisconsinHolocene glacial transition. Science, 270 (5235), 455-458.

Deblonde, G. and W. R. Peltier, 199I. Simulations of continental ice sheet growth over the last glacial-interglacial cycle: experiments with a onelevel seasonal energy balance model including realistic geography. , f. Geophys. Res., 96 D5), 91899215.

Denton, G. H. and T.J. Hughes, eds. 1981. The last great ice sheels. New York, etc., John Wiley and Sons.

Gates, W. L. 1976a. Modeling the ice age climate. Science, 191 4232), $1138-1144$.

Gates, W. L. 1976b. The numerical simulation of an ice-age climate with a global general circulation model. J. Atmos. Sic., 33, 1844-1873.

Grosswald, M. G. 1988. An Antarctic-style ice sheet in the Northern Hemisphere; toward a new global glacial theory. Polar Geogr. Geol., 12 4), $239-267$.

Grosswald, M. G. and T.J. Hughes. 1995. Paleoglaciology's grand unsolved problem. J. Glaciol., 41 (138), 31.3-332.

Higham, M., M. Craven, A. Ruddell and I. Allison. 1997. Snow-accumulation distribution in the interior of the Lambert Glacier basin, Antarctica. Ann. Glaciol., 25, 412-417.

Huybrechts. P. 1990. A 3-D model for the Antarctic ice sheet: a sensitivity study on the glacial-interglacial contrast. Climate Dyn., 5 2), $79-92$.

Huybrechts, P. 1992. The Antarctic ice sheet and environmental change: a three-dimensional modelling study. Ber. Polarforsch. 99.

Huybrechts, P. and S. T'siobbel. 1995. Thermomechanical modelling of Northern Hemisphere ice sheets with a two-level mass-balance parameterization. Ann. Glaciol., 21, II1-116.

Jaeger, L. 1976. Monatskarten des Niederschlags für die ganze Erde. Ber. Disch. Wiellerdienstes, 18 (139).

Jouzel, J. and 6 others, 1987. Vostok ice core: a continuous isotope temperature record over the last climatic cycle (160,000 years). Nature, $329(6138)$, $403-408$.

Levesque, A. J., L. C. Cwynar and I. R. Walker. 1997. Exceptionally steep north-south gradients in lake temperatures during the last deglaciation. Nature, 385 (6615), 423-426.

Lorius, C. and 6 others. 1985. A 150,000-year climatic record from Antarctic ice. Nalure, 316 (6029), 591-596.

Lorius, C., G. Raisbeck, J. Jouzel and D. Raynaud. 1989. Long-term environmental records from Antarctic ice cores. In Oeschger, H. and C. C. Langway, Jr, eds. The environmental record in glaciers and ice sheets. Chichester, etc., John Wiley and Sons, 343-361.

MacAveal, D. R. and R. H. Thomas. 1982. Numerical modeling of ice-shelf motion. Amn. Glaciol., 3, $189-194$.

Manabe, S. and A. J. Broccoli. 1985. The influence of continental ice sheets on the climate of an ice age. 7. Geophys. Res., 90 (DI), $2167-2190$.

Marsiat, I. 1995. The waxing and waning of the Northern Hemisphere ice sheets. Amm. Glaciol., 21. 96-102.

Mason. B. J. 1979. Some results of climate experiments with numerical models. In World Climate Conference. Geneva, World Meteorological Organization, 210-242. (WMO Publication 537.)

Mavrakis, E. 1993. Time dependent, three-dimensional modelling of the dynamics and thermodynamics of large ice masses. (M.Sc. thesis, University of Melbourne.

O'Farrell, S. P., J. L. Mc Gregor, L. D. Rotstayn, W. F. Budd, C.. Zweck and R. Warner. 1997. Impact of transient increases in atmospheric $\mathrm{CO}_{2}$ on the accumulation and mass balance of the Antarctic ice sheet. Ann. Glaciol., 25, 137-144.

Rind, D. 1987. Components of the ice age circulation. 7. Geophys. Res., 92 D 4, $4241-4281$.

Rind, D. and D. M. Peteet. 1985. Terrestrial conditions at the last glacial maximum and CLIMAP sea-surface temperature estimates: are they consistent? Quat. Res., 24(1), 1-22.

Smith. I. N.. W. F. Budd and P. Reid. 1998. Model estimates of Antarctic accumulation rates and their relationship to temperature changes. $\mathrm{Ann}$. Glaciol., 27 (see paper in this volume).

Webb, R. S., D. H. Rind, S. J. Lehman, R. J. Healy and D. Sigman. 1997. Influence of ocean heat transport on the climate of the Last Glacial Maximum. Nature, 385 6618). 695-699.

Weertman, J. 1957. Deformation of floating ice shelves. 7. Glaciol., 3 21), 38-42. 